1 Cates W, Wasserheit JN. Genital chlamydial infections: epidemiology and reproductive sequelae. Am J Obstet Gynecol 1991;164:1771-81.

2 Centers for Disease Control. Chlamydia trachomatis genital infectionsUnited States 1995. JAMA 1997;277: 952-3.

3 Scholes D, Stergachis A, Heidrich FE, Andrilla H, Holmes KK, Stamm WE. Prevention of pelvic inflammatory diseases by screening for cervical chlamydial infection. N Engl J Med 1996;334:1352-66.

4 Chief Medical Officer. Main report of the CMO's expert advisory group on Chlamydia trachomatis. London: Department of Health, 1998.

5 Ainslie DC. AIDS, sexual ethics and the duty to warn. Hastings Center Report 1999;29:26-35.

6 Black N. Why we need qualitative research.J Epidemiol Community Health 1994;48:425-6.

7 Buston K, Parry-Jones W, Livingston M, Bogan A, Wood S. Qualitative research. Br J Psychiatry 1998;172:197-9.

8 Smith JA. Beyond the divide between cognition and discourse: using interpretative phenomenological analysis in health psychology. Psychol Health 1996;11:261-71
9 Flowers P, Smith JA, Sheeran P, Beail N. Health and romance: understanding unprotected sex in relationships between gay men. $\mathrm{Br} J$ Health Psychology 1997;1:73-86.

10 SIGN. Management of genital Chlamydia trachomatis infection: a national clinical guideline. Scottish Intercollegiate Guidelines Network: Edinburgh, 2000.

11 Holgate HS, Longman C. Some people's psychological experiences of attending a sexual health clinic and having a sexually transmitted infection. J R Soc Health 1998;118:94-6.

12 Redfern N, Hutchinson S. Women's experiences of repetitively contracting sexually transmitted diseases. Health Care for Women Int 1994;15:423-

13 Kellock DJ, Piercy H, Rogstad KF. Knowledge of Chlamydia trachomatis infection in genitourinary medicine clinic attenders. Sex Trans Inf 1999:75:36-40.

14 Santer M, Wyke S, Warner P. Screening women for chlamydia infection in general practice using urine testing. Edinburgh: Chief Scientist Office, 2000. (Accepted 28 September 2000)

\title{
Birth weight and cognitive function in the British 1946 birth cohort: longitudinal population based study
}

\author{
Marcus Richards, Rebecca Hardy, Diana Kuh, Michael E J Wadsworth
}

\begin{abstract}
Objective To examine the association between birth weight and cognitive function in the normal population.

Design A longitudinal, population based, birth cohort study.

Participants 3900 males and females born in 1946. Main outcome measures Cognitive function from childhood to middle life (measured at ages $8,11,15$, 26 , and 43 years).

Results Birth weight was significantly and positively associated with cognitive ability at age 8 (with an estimated standard deviation score of 0.44 (95\% confidence interval 0.28 to 0.59 )) between the lowest and highest birthweight categories after sex, father's social class, mother's education, and birth order were controlled for. This association was evident across the normal birthweight range $(>2.5 \mathrm{~kg})$ and so was not accounted for exclusively by low birth weight. The association was also observed at ages 11,15 , and 26, and weakly at age 43 , although these associations were dependent on the association at age 8 . Birth weight was also associated with education, with those of higher birth weight more likely to have achieved higher qualifications, and this effect was accounted for partly by cognitive function at age 8 .

Conclusions Birth weight was associated with cognitive ability at age 8 in the general population, and in the normal birthweight range. The effect at this age largely explains associations between birth weight and cognitive function at subsequent ages. Similarly, the association between birth weight and education was accounted for partly by earlier cognitive scores.
\end{abstract}

\section{Introduction}

Small size at birth is associated with a range of adverse health outcomes, ${ }^{1}$ including poor cognitive development, ${ }^{2}$ an effect that is largely unconfounded by features of the family environment, such as socioeconomic status and birth order. Although most cognitive studies focus on clinically low birthweight groups, confirmation of this association across the full birthweight range in the normal population is of particular interest, since this would imply that explanatory factors are similarly distributed in the general population. One early such population based study found that verbal reasoning scores at age 11 increased with increasing birth weight. ${ }^{3}$ This association was also detected in early adulthood, ${ }^{4}$ although not in later life.

We examined the association between birth weight and cognitive function in the normal population using data from the British 1946 birth cohort. A particular advantage of this cohort is the use of repeated cognitive assessments throughout life, beginning at age 8 years and extending to age 43 , thus allowing the investigation of relative change in cognitive function according to birth weight. To investigate an outcome with specific functional consequences, we also examined the association between birth weight and educational attainment.

\section{Methods}

\section{The 1946 birth cohort}

Participants were drawn from the Medical Research Council's national survey of health and development, a birth cohort study stratified by social class and initially consisting of 5362 people selected from all births that occurred in England, Scotland, and Wales during one week in March 1946. ${ }^{6}$ Information about sociodemographic factors and medical, cognitive, and psychological function has been obtained at intervals by interview and examination-most recently in 1989 at age 43 , when the sample size was 3262 ; the sample is regarded as representative of the UK population born legitimately and singly in the years immediately after the second world war.

\section{Cognitive measures and educational attainment} Various cognitive measures were used. ${ }^{8}{ }^{9}$ Children were tested at age 8 on reading comprehension, word pronunciation, vocabulary, and non-verbal reasoning;
MRC National Survey of Health and Development, University College London, London WC1E 6BT

Marcus Richards MRC scientist

Rebecca Hardy

MRC scientist

Diana Kuh

MRC senior scientist

Michael E J

Wadsworth

director

Correspondence to: M Richards, MRC

National Survey of

Health and

Development,

University College

London,

Department of

Epidemiology and

Public Health,

London

WC1E 6BT

m.richards@ucl.

ac.uk

BMJ 2001;322:199-203 
Table 1 Mean differences (95\% confidence intervals) in standardised cognitive score by birthweight group compared with middle birthweight group $(3.01-3.50 \mathrm{~kg})$ for all cognitive tests and results of statistical tests for heterogeneity across categories of birth weight

\begin{tabular}{|c|c|c|c|c|c|}
\hline \multirow[b]{3}{*}{ Test age (years) } & \multicolumn{4}{|c|}{ Birth weight (kg) } & \multirow{3}{*}{$\begin{array}{l}P \text { value (and for } \\
\text { normal birth } \\
\text { weight) }\end{array}$} \\
\hline & \multirow[b]{2}{*}{ Low $(0-2.50)$} & \multicolumn{3}{|c|}{ Normal } & \\
\hline & & $2.51-3.00$ & $3.51-4.00$ & $4.01-5.00$ & \\
\hline $8(n=3773)$ & $-0.27(-0.42$ to -0.11$)$ & $-0.06(-0.16$ to 0.03$)$ & $0.13(0.05$ to 0.21$)$ & $0.03(-0.08$ to 0.14$)$ & $<0.001(<0.001)$ \\
\hline $11(\mathrm{n}=3618)$ & $-0.23(-0.39$ to -0.06$)$ & $-0.09(-0.18$ to 0.01$)$ & 0.08 (0.00 to 0.15$)$ & $-0.08(-0.19$ to 0.03$)$ & $<0.001(0.003)$ \\
\hline $15(n=3553)$ & $-0.29(-0.46$ to -0.13$)$ & $-0.11(-0.20$ to -0.01$)$ & $0.06(-0.02$ to 0.14$)$ & $-0.05(-0.16$ to 0.06$)$ & $<0.001(0.008)$ \\
\hline $26(n=3115)$ & $-0.33(-0.51$ to -0.16$)$ & $-0.08(-0.19$ to 0.02$)$ & $0.03(-0.06$ to 0.11$)$ & $-0.08(-0.20$ to 0.05$)$ & $0.001(0.124)$ \\
\hline \multicolumn{6}{|l|}{ 43: } \\
\hline Verbal memory $(n=2522)$ & $-0.17(-0.37$ to 0.02$)$ & $-0.08(-0.20$ to 0.03$)$ & $-0.07(-0.17$ to 0.02$)$ & $-0.17(-0.31$ to -0.04$)$ & $0.079(0.076)$ \\
\hline Search accuracy $(n=2575)$ & $-0.10(-0.29$ to 0.09$)$ & $-0.03(-0.15$ to 0.08$)$ & $-0.01(-0.09$ to 0.09$)$ & $0.02(-0.11$ to 0.16$)$ & $0.799(0.901)$ \\
\hline Search speed $(n=2574)$ & $-0.03(-0.22$ to 0.16$)$ & $-0.05(-0.17$ to 0.06$)$ & $-0.05(-0.14$ to 0.04$)$ & $-0.07(-0.21$ to 0.07$)$ & $0.776(0.620)$ \\
\hline
\end{tabular}

at age 11 on verbal and non-verbal intelligence, arithmetic, word pronunciation, and vocabulary; and at age 15 on verbal and non-verbal intelligence (the AH4 test), reading comprehension, and mathematics. As adults they were tested at age 26 on reading comprehension and at age 43 on verbal memory (word list learning), timed letter search (speed and accuracy). ${ }^{10}$ All scores for participants with a valid score for each test were standardised to give a mean of 0 and a standard deviation of 1 . Global scores representing overall cognitive function at ages $8,11,15$, and 26 were obtained by setting the standard deviation of the distribution of the sum of these scores to one. Test scores at age 43 were kept separate. The highest educational or training qualification achieved by age 26 was classified either as ordinary secondary qualifications $(\mathrm{O}$ levels and their training equivalents) or less, or as advanced secondary education (A levels and their equivalents) or degree level or equivalent.

\section{Statistical methods}

Birth weight was split into five categories $(<2.51 \mathrm{~kg}$, 2.51-3.00 kg, 3.01-3.50 kg, 3.51-4.00 kg, and 4.01$5.00 \mathrm{~kg}$ ). The association between birth weight and cognitive function at age 8 was investigated with regression models, with adjustment for sex, father's social class, mother's education, birth order, and mother's age. The relation between birthweight category and cognitive score was tested for linearity. To test whether change in cognitive function differed across the birthweight categories, each cognitive score (from age 11 to age 43) in this adjusted model was further adjusted for the score at the previous age (conditional model for change). All tests of association between birth weight and cognitive function were also carried out on the groups with normal birth weight (that is, $>2.51 \mathrm{~kg}$ ) to check that any statistically significant effect was not driven by the lowest birthweight category.

The effect of birth weight on education was assessed by logistic regression, with adjustment for the same confounders as for the cognitive function models.

\section{Results}

\section{Missing data}

Seven hundred and sixty two cohort members had not undergone cognitive testing at any age; 21 of these had missing information on birth weight. Of the 4600 cohort members with at least one recorded cognitive test score, $3900(85 \%)$ had complete information on birth weight and confounders and could therefore be included in the analyses. Those with missing information had lower mean cognitive scores at ages 8 $(\mathrm{P}=0.09), 11(\mathrm{P}=0.02), 15(\mathrm{P}=0.05)$, and $26(\mathrm{P}=0.1)$, but not at age 43 ( $\mathrm{P}>0.1$ for all tests), compared with others. Among the 3900 included in at least one model, those with a missing cognitive score at any age were more likely to have a missing score at subsequent ages. Furthermore, a lower test score at one age was associated with a greater likelihood of a missing score at the following age.

\section{Birth weight and cognitive function}

Regression coefficients for the effect of birth weight grouped into five categories on cognitive scores indicated increasing mean cognitive function with increasing birth weight for the first four birthweight categories, followed by a decrease in cognitive score at the highest birthweight category at ages $8,11,15$, and 26 (table 1). At ages 8, 11, and 15 the significant association was still apparent across the four normal birthweight categories $(\mathrm{P}<0.01$ in all cases), but the association with cognitive function at age 26 was due largely to the difference in mean score between those of low birth weight and those of normal birth weight (table 1). At age 43, birth weight had no significant effect on any of the test scores (table 1).

Adjustment for sex, father's social class, mother's education, birth order, and mother's age strengthened the association between birth weight and cognitive function and made the effect consistent with a linear trend for test scores at ages 8 to 26 (table 2). These trends remained significant $(\mathrm{P}<0.001)$ when analyses were restricted to the four normal birthweight categories. At age 43 the evidence of a gradient was weak (table 3). An effect was seen for both verbal memory and search accuracy, but this was due partly to those with low birth weight having lower mean scores than those with normal birth weight. Adjustment for birth order in these models had the effect of increasing the coefficient of those with the highest birth weight, as birth order was related positively to birth weight but negatively to cognitive function.

A positive linear association $(\mathrm{P}<0.001)$ existed between birthweight category and cognitive score at age 8 , with an estimated standard deviation score of $0.44(95 \%$ confidence interval 0.28 to 0.59$)$ between the lowest and highest birthweight groups (table 2). Results of the conditional regression models showed that change in cognitive ability between every pair of 
ages was not substantially different between birthweight groups after adjustment for the cognitive test score for the previous age (tables 2 and 3). Thus the effect of birth weight on test scores at ages 11,15 , and 26 was accounted for largely by its effect earlier in life.

\section{Birth weight and educational attainment}

Logistic regression showed a significant effect of birth weight on education, with increasing birth weight being associated with higher educational attainment (odds ratio for an increase in birthweight category = $1.12 ; 95 \%$ confidence interval 1.04 to 1.20 ). As with the cognitive tests, this effect became stronger on addition of the family and social background confounders $(1.16 ; 1.07$ to 1.26$)$ and was also observed across the normal birthweight range. The effect was substantially attenuated after the cognitive score at age 8 was added to the model.

\section{Discussion}

In a large UK birth cohort, we found that that birth weight was associated with cognitive ability through childhood and early adulthood in the normal population, although the effect was less marked in midlife. Birth weight was significantly associated with cognitive function at age 8 years, with cognitive scores increasing across the four lowest birthweight categories, then declining at the highest birthweight category. Adjustment for sex, father's social class, mother's education, mother's age, and birth order strengthened this overall association, and the trend became more linear through raising the coefficient for the highest birthweight category. These results are broadly compatible with those of Record et $\mathrm{al}^{3}$ and support their suggestion that birth weight is related to cognitive performance independently of social background. Importantly, this association was observed within the normal birthweight range (that is, $>2.5 \mathrm{~kg}$ ) at ages 8,11 , and 15 , suggesting that the significant results are not just accounted for by low birth weight in the normal population. Birth weight was also related to educational attainment at these ages, an association previously reported in 17 year olds born small for gestational age, ${ }^{11}$ thus providing evidence that the association between birth weight and cognition has functional implications.

The association between birth weight and cognitive function was maintained across adolescence (ages 11 and 15) and early adulthood (age 26), the latter confirming the results of Sorensen et al. ${ }^{4}$ Conditional regression modelling showed, however, that cognitive growth between ages 8 and 26 was similar across all birthweight groups. Thus, although the influence of birth weight on cognitive function was maintained into adulthood, this influence was largely driven by the effect of birth weight on cognition at age 8 .

The evidence of a gradient with birth weight was much weaker at age 43 , although the shift in the nature of the tests-namely, from the psychometric attainment tests used earlier to the test of memory-means that the results should be interpreted with caution. Martyn et al found no association between birth weight and IQ in midlife to later life. ${ }^{5}$ Adult environmental influences, particularly educational and occupational attainment, may overshadow perinatal factors by middle life.
Table 2 Mean differences (95\% confidence intervals) in standardised cognitive score for each birthweight category compared with middle birthweight category for tests at ages $8,11,15$, and 26 years

\begin{tabular}{|c|c|c|c|c|}
\hline Birth weight (kg) & $\begin{array}{c}\text { No }(\%) \text { of } \\
\text { participants }\end{array}$ & Adjusted* & $\begin{array}{c}\text { Conditional on previous } \\
\text { test score }\end{array}$ & $P$ valueł \\
\hline \multicolumn{5}{|c|}{ Age 8 years $(n=3773)$ : } \\
\hline $0-2.50$ & $174(4.6)$ & $-0.25(-0.40$ to -0.12$)$ & - & $<0.001$ \\
\hline $2.51-3.00$ & $618(16.4)$ & -0.06 ( -0.15 to 0.02$)$ & & \\
\hline $3.01-3.50$ & $1319(35.0)$ & 0 & & \\
\hline $3.51-4.00$ & $1242(32.9)$ & 0.16 (0.09 to 0.23$)$ & & \\
\hline $4.01-5.00$ & $420(11.1)$ & 0.18 (0.08 to 0.28$)$ & & \\
\hline \multicolumn{5}{|c|}{ Age 11 years $(n=3527)$ : } \\
\hline $0-2.50$ & $155(4.4)$ & $-0.21(-0.36$ to -0.07$)$ & $-0.02(-0.12$ to 0.07$)$ & 0.51 \\
\hline $2.51-3.00$ & $586(16.6)$ & $-0.09(-0.17$ to 0.00$)$ & $-0.04(-0.09$ to 0.02$)$ & \\
\hline $3.01-3.50$ & $1233(35.0)$ & 0 & 0 & \\
\hline $3.51-4.00$ & $1159(32.9)$ & $0.11(0.04$ to 0.18$)$ & $-0.01(-0.05$ to 0.04$)$ & \\
\hline $4.01-5.00$ & $394(11.2)$ & $0.08(-0.02$ to 0.18$)$ & $-0.04(-0.11$ to 0.02$)$ & \\
\hline \multicolumn{5}{|c|}{ Age 15 years $(n=3383)$ : } \\
\hline $0-2.50$ & $151(4.5)$ & $-0.24(-0.39$ to -0.10$)$ & $-0.06(-0.14$ to 0.02$)$ & 0.14 \\
\hline $2.51-3.00$ & $564(16.7)$ & $-0.12(-0.20$ to -0.03$)$ & $-0.04(-0.09$ to 0.00$)$ & \\
\hline $3.01-3.50$ & $1174(34.7)$ & 0 & 0 & \\
\hline $3.51-4.00$ & $1117(33.0)$ & $0.06(-0.01$ to 0.13$)$ & $-0.03(-0.07$ to 0.00$)$ & \\
\hline $4.01-5.00$ & $377(11.1)$ & $0.08(-0.02$ to 0.18$)$ & $0.00(-0.05$ to 0.05$)$ & \\
\hline \multicolumn{5}{|c|}{ Age 26 years $(n=2888)$ : } \\
\hline $0-2.50$ & $135(4.7)$ & $-0.24(-0.40$ to -0.08$)$ & $-0.01(-0.12$ to 0.09$)$ & 0.96 \\
\hline $2.51-3.00$ & $471(16.3)$ & $-0.09(-0.18$ to 0.01$)$ & $0.01(-0.06$ to 0.07$)$ & \\
\hline $3.01-3.50$ & $1006(34.8)$ & 0 & 0 & \\
\hline $3.51-4.00$ & $966(33.5)$ & $0.06(-0.02,0.14)$ & $0.02(-0.04,0.07)$ & \\
\hline $4.01-5.00$ & $310(10.7)$ & $0.09(-0.03$ to 0.20$)$ & $0.02(-0.05$ to 0.10$)$ & \\
\hline
\end{tabular}

*For sex, father's social class, mother's education, birth order, and mother's age.

†Adjusted for all factors listed above, as well as for cognitive score at the previous age.

$\Varangle P$ value for test for heterogeneity across birthweight groups for conditional analysis.

Table 3 Mean differences (95\% confidence intervals) in standardised cognitive score for each birthweight category compared with middle birthweight category for tests at age 43 years

\begin{tabular}{|c|c|c|c|c|}
\hline Birth weight (kg) & $\begin{array}{l}\text { No (\%) of } \\
\text { participants }\end{array}$ & Adjusted* & $\begin{array}{l}\text { Conditional on } \\
\text { previous test score }\end{array}$ & $P$ valueł \\
\hline \multicolumn{5}{|c|}{ Verbal memory $(\mathrm{n}=2320)$ : } \\
\hline $0-2.50$ & $106(4.6)$ & $-0.17(-0.36$ to 0.02$)$ & $-0.07(-0.24$ to 0.10$)$ & 0.68 \\
\hline $2.51-3.00$ & $379(16.3)$ & $-0.12(-0.24$ to -0.01$)$ & $-0.07(-0.17$ to 0.03$)$ & \\
\hline $3.01-3.50$ & $825(35.6)$ & 0 & 0 & \\
\hline $3.51-4.00$ & $771(33.2)$ & $0.06(-0.02$ to 0.14$)$ & $-0.02(-0.10$ to 0.06$)$ & \\
\hline $4.01-5.00$ & $239(10.3)$ & $0.09(-0.03$ to 0.20$)$ & $-0.02(-0.14$ to 0.10$)$ & \\
\hline \multicolumn{5}{|c|}{ Visual search accuracy $(n=2364)$ : } \\
\hline $0-2.50$ & $110(4.7)$ & $-0.12(-0.32$ to 0.07$)$ & $-0.05(-0.24$ to 0.14$)$ & 0.54 \\
\hline $2.51-3.00$ & $384(16.2)$ & $-0.06(-0.18$ to 0.06$)$ & $-0.04(-0.15$ to 0.08$)$ & \\
\hline $3.01-3.50$ & $840(35.5)$ & 0 & 0 & \\
\hline $3.51-4.00$ & 787 (33.3) & $0.01(-0.09$ to 0.11$)$ & $0.00(-0.09$ to 0.09$)$ & \\
\hline $4.01-5.00$ & $243(10.3)$ & $0.10(-0.04$ to 0.25$)$ & $0.10(-0.04$ to 0.23$)$ & \\
\hline \multicolumn{5}{|c|}{ Visual search speed $(n=2363)$ : } \\
\hline $0-2.50$ & $110(4.7)$ & $-0.07(-0.27$ to 0.13$)$ & $-0.04(-0.24$ to 0.15$)$ & 0.60 \\
\hline $2.51-3.00$ & $384(16.3)$ & $-0.10(-0.21$ to 0.02$)$ & $-0.09(-0.21$ to 0.03$)$ & \\
\hline $3.01-3.50$ & $839(35.5)$ & 0 & 0 & \\
\hline $3.51-4.00$ & $787(33.3)$ & $-0.04(-0.14$ to 0.06$)$ & $-0.04(-0.14$ to 0.05$)$ & \\
\hline $4.01-5.00$ & $243(10.3)$ & $0.02(-0.12$ to 0.16$)$ & $0.02(-0.13$ to 0.16$)$ & \\
\hline
\end{tabular}

*For sex, father's social class, mother's education, birth order, and mother's age.

$\dagger$ Adjusted for all factors listed above, as well as for cognitive score at the previous age.

$\ddagger \mathrm{P}$ value for test for heterogeneity across birthweight groups for conditional analysis.

Evidence exists of such environmental overshadowing in this context in childhood. ${ }^{12}{ }^{13}$ Pathways between early family background, adult educational and occupational attainment, and midlife cognitive function are currently under investigation in the national survey of health and development.

\section{Limitations of study}

Some limitations of the current study should be noted.

Firstly, data on gestational age was not collected, which 
limits the interpretation of birth weight as an index of fetal growth in this cohort. We are currently investigating postnatal growth ${ }^{14}$ as an explanatory factor in the current findings. Secondly, cohort members with missing information on birth weight and confounders had lower cognitive scores at ages eight, 11, 15, and 26 than those with complete information. However, the unadjusted associations between birth weight and cognitive score in analyses of cohort members with data for birth weight and cognitive function but not for confounders were similar to those for whom information on confounders was complete. These findings suggest that the relation between birth weight and cognitive function was not sensitive to the sample selection. Thirdly, our analyses were adjusted for important features of the early family background, particularly those strongly associated with cognitive development, such as father's social class and parental education. These are crude measures, however, of sociodemographic background, encompassing a range of factors potentially important for birth weight, such as smoking, mother's height, physical work, psychosocial stress, and nutrition. ${ }^{15}$ Thus we cannot rule out the possibility that residual effects of social background remained after statistical adjustment.

\section{Interpretation}

Caution is needed in the interpretation of repeated tests of birth weight with different outcomes, particularly when different numbers are included in each analysis. The problem of assessing cognitive change over time is compounded because there is no single cognitive test that can be used throughout life, as cognitive measures must change with cognitive development. Repeated measures models, unlike the conditional regression models used here, are dependent on the outcome scale used, and standardised scores may not be a realistic scaling in this respect as they assume no cognitive growth with age, and no increased variation in scores with age occurs. ${ }^{16}$ Further investigation of these data using such models is in progress. We took a more simple approach here, considering the association between birth weight at the earliest time point then assessing the influence of birth weight on subsequent relative changes in cognitive function. Regression to the mean ${ }^{17}{ }^{18}$ occurs when fitting such models, as they assume that the score at the earliest age is fixed (that is, measured without error). However, for the measurement error to have a substantial impact on the association between birth weight and change in cognitive score presented here, the cognitive test scores would have to be notably unreliable.

If birth weight is associated with cognitive function in the general population, explanatory factors must be similarly distributed in the normal population. From this perspective, birth weight is strongly related to head circumference at birth ${ }^{1}$ - which in turn is closely correlated with brain size ${ }^{19}$ and so is associated with childhood cognitive function. ${ }^{20}$ The most parsimonious explanation for the current results, therefore, is that the relations between these variables, established for comparisons between low and normal birthweight children, also hold across the normal range in the general population. At the neurochemical level, birth weight is associated with insulin-like growth factors, ${ }^{21}$ and interest has been growing in the role of glucose

\section{What is already known on this topic}

Low birth weight is associated with poor cognitive development

Few studies have examined this association across the full birthweight range in the normal population

\section{What this study adds}

Birth weight is significantly associated with cognitive ability at age 8 years, through adolescence, and into early adulthood, independent of social background

The associations between birth weight and cognitive function at ages 8,11 , and 15 are evident across the normal birthweight range $(>2.5 \mathrm{~kg})$ and so are not accounted for exclusively by low birth weight

Birth weight is also associated with educational attainment, suggesting that the association between birth weight and cognition may have functional implications

metabolism, insulin, and insulin-like growth factors in the development of the central nervous system and cognitive function. ${ }^{22}{ }^{23}$ How these processes are distributed in the population is not known. However, three key risk factors for low birth weight-nutrition, smoking, and alcohol misuse ${ }^{15}$-all influence brain glucose concentrations or the function of insulin-like growth factors, ${ }^{124}{ }^{25}$ although the pathways are likely to be complex. A reduction in birth weight after maternal starvation in the Dutch famine cohort of the 1940s, for example, was not associated with subsequent cognitive performance. ${ }^{26}$

Contributors: MR initiated and coordinated the formulation of the core study ideas, and RH, DK, and MEJW helped to develop these ideas. RH designed and performed the statistical analysis. The paper was written jointly by all authors. MR will act as guarantor for this paper.

Funding: The Medical Research Council provided funding for the MRC national survey of health and development, and financial support for all authors of this article.

Competing interests: None declared.

1 Barker DJP. Mothers, babies and health in later life. Edinburgh: Churchill Livingstone, 1998

2 Breslau N. Psychiatric sequelae of low birthweight. Epidemiol Rev 1995; 17:96-106

3 Record RG, Mckeown T, Edwards JH. The relation of measured intelligence to birth weight and duration of gestation. Ann Hum Genet 1969;33:71-9.

4 Sorensen HT, Sabroe S, Olsen J, Rothman KJ, Gilman MW, Fischer P. Birth weight and cognitive function in young adult life: historical cohort study. BMI 1997:315:401-3.

5 Martyn CN, Gale CR, Sayer AA, Fall C. Growth in utero and cognitive function in adult life: follow up study of people born between 1920 and 1943. BMJ 1996;312:1393-6.

6 Wadsworth MEJ. The imprint of time: childhood, history and adult life. Oxford: Clarendon Press, 1991.

7 Wadsworth MEJ, Mann SL, Rodgers B, Kuh DL, Hilder WS, Yusuf EJ. Loss and representativeness in a 43 year follow-up of a national birth cohort. J Epidemiol Community Health 1992;46:300-4.

Pigeon DA. Tests used in the 1954 and 1957 surveys. In: Douglas JWB, ed. The home and the school. London: Macgibbon and Kee, 1964. (Appendix 1.)

9 Pigeon DA. Details of the fifteen years tests. In: Douglas JWB, Ross JM, Simpson HR, eds. All our future. London: Davies, 1968. (Appendix 1.)

10 Richards M, Kuh D, Hardy R, Wadsworth M. Lifetime cognitive function and timing of the natural menopause. Neurology 1999;52:308-14. 
11 Paz I, Gale R, Laor A, Danon YL, Stevenson DK, Seidman DS. The cognitive outcome of full-term small for gestational age infants at late adolescence. Obstet Gynecol 1995;85:452-6.

12 Fawer CL, Besnier S, Forcada M, Buclin T, Calame A. Influence of perinatal, developmental and environmental factors on cognitive abilities of preterm children without major impairments at 5 years. Early Hum Dev 1995;43:151-64.

13 Illsley R, Mitchell RG, eds. Low birth weight: a medical, psychological and social study. Chichester: John Wiley, 1984

14 Lucas A, Fewtrell MS, Cole TJ. Fetal origins of adult disease-the hypothesis revisited. BMJ 1999;319:245-9.

15 Kline J, Stein Z, Susser M. Conception to birth-epidemiology of prenatal development. New York: Oxford University Press, 1989.

16 Plewis I. Statistical methods for understanding cognitive growth: a review, a synthesis and an application. Br J Math Stat Psychol 1996;49:25-42.

17 Bland JM, Altman DG. Regression towards the mean. BMJ 1994;308:1499.

18 Bland JM, Altman DG. Some examples of regression to the mean. BMJ 1994;309:780.

19 Cook RWI, Lucas A, Yudkin PLN, Pryse-Davies J. Head circumference as a index of brain weight in the fetus and newborn. Early Hum Dev 1977;1:145-9.
20 Nelson KB, Deutschberger J. Head size at one year as a predictor of four year IQ. Dev Med Child Neurol 1970;12:487-95.

21 Fall CHD, Pandit AN, Law CM, Yajnik CS, Clark PM, Breier B, et al. Size at birth and plasma insulin-like growth factor-1 concentrations. Arch Dis Child 1995;73:287-93.

22 De Pablo F, de la Rosa EJ. The developing CNS: a scenario for the action of proinsulin, insulin and insulin-like growth factors. Trends Neurosci $1995 ; 18: 143-50$.

23 Wickelgren I. Tracking insulin to the mind. Science 1998;280:517-9.

24 Eckstein LW, Shibley IA, Pennington JS, Carver FM, Pennington SN. Changes in brain glucose levels and glucose transporter protein isoforms in alcohol- or nicotine-treated chick embryos. Brain Res Dev Brain Res 1997;103:59-65.

25 Singh SP, Ehmann S, Snyder AK. Ethanol-induced changes in insulin-like growth factors and IGF gene expression in the fetal brain. Proc Soc Exp Biol Med 1996;212:349-54.

26 Stein ZA, Susser M, Saenger G, Marolla F. Famine and human development: the Dutch hunger winter of 1944/45. New York: Oxford University Press, 1975

(Accepted 20 October 2000)

\section{Insulin-like growth factor and cognitive function}

Insulin-like growth factors (IGFs) are peptides that regulate the growth, metabolism, survival, and differentiation of cells and are regulated by growth hormone. Both IGF-I and IGF-II consist of small peptides that share about $50 \%$ homology with proinsulin and are produced chiefly by the liver. IGF-I is an important cell growth regulator, but the role of IGF-II is less clear. IGF-II acts mainly via IGF-I receptors; IGF-II receptors do exist, but their role is believed simply to mop up IGF-II, rather than act as signalling receptors.

In contrast with other peptide growth factors, there is considerable evidence indicating that the IGFs play a critical role in determining overall (somatic) body growth in addition to contributing to local tissue regulation. A great deal of associative data show that IGF and IGF receptors, and growth hormone and growth hormone receptors, are located in the parts of the brain that are responsible for learning and memory (such as the hippocampus). It is feasible that early in life, IGFs and growth hormone play a role in the development of these areas of the brain, which could then explain associations between body size and subsequent measures of cognitive functions.

There has also been much speculation that relative IGF-I or growth hormone deficiency could contribute to the deterioration of cognitive functions observed in elderly people. Several studies in the United States have shown that giving growth hormone to elderly people reduces their body fat and increases lean body mass, but these same studies have produced equivocal data about memory function, and the methodology of the studies has been much criticised. Other studies have shown that giving growth hormone to adults with growth hormone deficiency does improve memory and is also associated with greater levels of circulating IGF-I, but controversy remains about what happens to cognitive function when growth hormone is given to children with growth hormone deficiency. ${ }^{1}$

On the basis on these observations, it has been suggested that circulating levels of IGF are related to cognitive function and that the administration of growth hormone may promote better cognitive function. But although IGFs may play a role in brain development early in life, it is much more difficult to come up with a mechanism that could explain how circulating IGF-I and cognitive function are connected in later life. Abi Berger science editor, BMJ

1 Van Dam PS, Aleman A, de Vries WR, Deijen JB, van der Veen EA, de Haan EH, et al. Growth hormone, insulin-like growth factor I and cognitive function in adults. Growth Horm IGF Res 2000;10(suppl B):S69-73.

\section{When cigarettes were acceptable}

These days, and in particular if you are a BMJ reader, it's hard to think of anything positive about cigarette smoking. Yet 50 years ago, and probably much more recently, doctors often recommended nicotine to their patients. And not just doctors. During my national service in the 1950s, I worked for a year as a ward orderly. This was an untrained dogsbody kind of job that probably doesn't exist these days, but which was an excellent education-a much broader concept than training-for someone heading towards medicine. Most patients on the orthopaedic ward in Bradford, where I spent six months, were smokers, as were the staff. One day a man was brought up from the accident and emergency department after emergency treatment for injuries that had resulted in a mid-thigh amputation of his right leg. He was put into a bed, howling and shouting in pain, and continued thus for some time, until the ward sister returned from her lunch break. Standing in the doorway of the big open ward, she called, "Give that man a cigarette." Within seconds of his first puff, so it seems to distant memory, he was quietened, and indeed, knowing the rapidity with which the drug travels from lips to brain, it probably wasn't much more. Can we offer any treatment in the year 2000 that is faster and more effective?

Simon Barley retired general practitioner, Sheffield 